\title{
Self-fertilization: a potential fertilization mode in an estuarine sabellid polychaete
}

\author{
Hwey-Lian Hsieh* \\ Institute of Zoology, Academia Sinica, Taipei, Taiwan 115, Republic of China
}

\begin{abstract}
The simultaneously hermaphroditic sabellid Laonome albicingillum Hsieh is the most dominant polychaete species in a mangrove estuary in northern Taiwan. Isolated individuals produced fertilized eggs which developed into normal larvae. Seminal receptacles were not found, indicating that individuals cannot store sperm. Ova, which were obtained directly from the coelom and inseminated by the same individual, developed into viable larvae and then settled successfully. The viability of embryos and newly settled larvae did not differ between self- and outcross fertilizations, indicating that self-fertilization has no immediate deleterious effects. Hypoosmotic seawater (salinity below $10 \%$ ) severely damaged sperm, resulting in stretched, perforated, or torn membranes. In contrast, seawater with 20 to $30 \%$ salinity did not injure sperm morphology. In estuarine environments, hyposaline ambient water presents such great constraints that selfing may be an advantageous fertilization alternative for this simultaneously hermaphroditic species that is sessile and has broadcast spawning.
\end{abstract}

KEY WORDS: Self-fertilıation - Hyposaline effects Simultaneous hermaphrodite Sabellid polychaete

\section{INTRODUCTION}

Outcross fertilization, as opposed to self-fertilization, has been regarded as the rule for many simultaneously hermaphroditic animals (Heath 1977, Maynard Smith 1978, Ghiselin 1987). The main deleterious effects of self-fertilization, known as inbreeding depression (e.g. Charlesworth \& Charlesworth 1987), appear at different stages of the life cycle, and include sperm inactivation (Kawamura et al. 1987), high developmental abnormality and slow growth of larvae (Beaumont \& Budd 1983) and small brood size (Hunter \& Hughes 1993). In contrast to the traditional perspective presented above, theoretical predictions and some available evidence in sessile organisms, such as plants and invertebrates, show that inbreeding depression is not always found (Knowlton \& Jackson 1993, Shields 1993). In these cases, the success of fertilization, embryogenesis, and larval metamorphosis may increase significantly in inbreeding matings (Grosberg 1987). Seed maturation also performs best in crosses with closely related, near neighbors (Waser 1993). Thus,

\footnotetext{
•E-mail: zocp@ccvax.sinica.edu.tw
}

there are certain ecological or evolutionary conditions that favor the evolution of inbreeding (Ghiselin 1969, Jain 1976).

In marine benthic invertebrates, sessile habit may limit encounters between mating partners, and broadcast spawning exposes gametes to wastage (Pennington 1985, Yund 1990, Brazeau \& Lasker 1992, Yund \& McCartney 1994, Levitan \& Petersen 1995). Free transfer of spermatophores breaks through the obstacles of sessile dwelling (e.g Hsieh \& Simon 1990), whereas synchronous spawning among individuals minimizes the loss of sperm (e.g. Levitan \& Petersen 1995). Selfing is another potential means for a hermaphroditic species to ensure fertilization. Moreover, in some habitats, such as estuaries, self-fertilization is greatly favored in hermaphrodites that are sessile and asynchronous broadcast spawners, because sperm are not exposed to osmotic shock (Clark 1981, Hintz \& Lawrence 1994) and also avoid becoming diluted.

In the mangrove estuary of the Tan-Shui River in northern Taiwan, the hermaphroditic sabellid Laonome albicingillum Hsieh (Hsieh 1995a) is the dominant polychaete species with a population density ranging from 600 to as high as 19000 ind. $\mathrm{m}^{-2}$ (Hsieh 1995b). 
When spawned, eggs in the process of emerging from the branchial crown have often already begun to cleave. These findings suggest that eggs may be fertilized by the same individual's sperm.

Water salinities in the Iower estuary of the Tan-Shui River vary from a seawater regime at flood tides (10 to $33 \%$ salinity) to a freshwater regime at ebb tides (0 to $18 \%$ salinity) (Shih et al. 1991, Wu et al. 1993). In the upper estuary, freshwater dominates, even at flood tides (0 to $15 \%$ salinity) (author's unpubl. data). Gametes spawned by adults living in the estuary are subjected to osmotic shock and dilution problems. Selffertilization may be a favored alternative if inbreeding does not cause severe inbreeding depression.

The purposes of the present study were to examine the likelihood and consequences of selfing in the sabellid Laonome albicingillum. Experiments were designed to examine whether self-fertilization occurred, whether there was sperm storage, and whether sclffertilized and outcrossed larvae differed significantly in survival and development. In addition, the selection pressures from estuarine environments for a selffertilization in L. albicingillum were further eluridated by examining the effects of hypoosmotic seawater on sperm morphology.

\section{MATERIALS AND METHODS}

Study organism. Laonome albicingillum is a tube dwelling species and is simultaneously hermaphroditic. Mature individuals range in length from 3 to $6 \mathrm{~cm}$, with the most anterior 10 abdominal segments producing ova and the subsequent 33 abdominal segments producing sperm. Gravid female segments are pale green, while male segments are milk-white in color. The reproductive season is long, running from fall (September-October) to late spring (April-May). Spawning occurs spontaneously under laboratory conditions and is asynchronous among individuals. Spawned eggs stick together loosely in thin mucous masses and are released from the branchial crown into the ambient water. Larvae settle within 26 to $33 \mathrm{~h}$ from fertilization (Hsieh 1995a, b).

Isolation experiment. This experiment was designed to test whether isolated individuals produce viable offspring. Adult individuals were collected from the field, and then gravid individuals were used for the experiments within $1 \mathrm{~d}$. Two treatments (control and isolation treatments) were set up as follows. In the control treatment, 3 individuals were kept together in a glass container in order to increase the chance of outcrossing; in the isolation treatment, only 1 individual was in each container. Individuals were randomly assigned to the control or the isolation treatments with 29 and 62 repli- cates, respectively. A total of 149 individuals were used. The containers, each $8.5 \mathrm{~cm}$ in diameter and $3.5 \mathrm{~cm}$ in height, were filled with $100 \mathrm{ml}$ of filtered seawater of $20 \%$ salinity $(S)$ and were gently aerated. Each trial was run for $4 \mathrm{~d}$. The specimens were not fed. Three trials were carried out from December 1993 to February 1994. For each treatment, the number of replicates producing offspring, the number of egg batches and larvae produced, and the number of larvae settled were recorded. Larvae settled on the bottom of the culture containers without the addition of inducing substances or sediment substrates. Newly settled individuals (juveniles) secreted a small amount of thin mucus, which surrounded their peristomial portion to anchor them to the bottom.

Coelomic ova experiment. This experiment tested whether the survival and development of offspring depended on the sperm donor. Individuals were dissected into 2 pieces al segment 16 or 17 . The anterior portion, which contains the head and female segments, was then transferred to a glass dish with clean, filtered seawater The few anterior segments of the posterior portion containing both female and male seğmiluis (i.e. segments 16 to 21 ) were separated and discarded. The remaining posterior portions, now containing only the male segments, were transferred to a separate glass dish filled with clean, filtered seawater. Both separated anterior (female) and posterior (male) segments were washed several times with clean, filtered seawater before coeloms were opened. In order to avoid contamination by sperm or ova, the above manipulations were done with cleaned scissors and forceps. Controls (sperm-free ova, see 'Results') showed that ova isolated by this method were free of sperm.

Coelomic ova were obtained by opening the female segments. Newly released mature ova were irregular but soon became spherical in shape. The mature ova, ranging from 140 to $180 \mu \mathrm{m}$ in diameter, had no visible nucleus but had a very thin and transparent membrane. Mature ova were randomly distributed into 3 glass bowls containing clean, filtered seawater. Male segments were kept moist with seawater and then opened to release sperm immediately before use. Three containers were designated for control, self-fertilization, and outcross treatments; ova were added with no sperm (control), with sperm from the same individual (selfing), and with sperm from another individual (outcross), respectively. Among 120 individuals examined from March to November 1994, 15 individuals (replicates) produced enough mature ova to conduct this experiment.

Each trial was run for $4 \mathrm{~d}$. Each container was gently aerated and kept in $20 \% S$ at room temperature. In each treatment, the number of fertilized ova was recorded (at the first and the second cleavage) and the 
percentages of fertilized ova that reached embryo and settlement stages, respectively, were calculated. The effects were analyzed using the $G$-test of independence (Sokal \& Rohlf 1981). In each $2 \times 2$ table, the 2 criteria were the fertilization modes, selfing and outcross, in which live and dead offspring were counted. All statistical calculations were produced using SAS software (SAS Institute 1985) and a Sparc 10 computer.

Tissue examination. To determine whether this species is capable of sperm storage, tissues were examined to establish whether there is sperm transfer between individuals. Individuals used were directly collected from the field in March and December 1993. Gravid individuals were fixed in Bouin's fixative soon after being brought back to the laboratory, usually within 1 to $2 \mathrm{~h}$ from the field collection. Individuals' tissues were then embedded in paraffin, and serially sectioned to a thickness of $5 \mu \mathrm{m}$. Four individuals were sectioned through the entire body with 2 individuals in cross and 2 in longitudinal section. Another 6 individuals were longitudinally sectioned through only the anterior portions of the body, which contain the branchial crown and the female segments. Sections were stained in Mayer's hematoxylin and eosin and then examined using a light microscope. According to the studies on the sperm storage in the polychaetes, seminal receptacles are blind, sac-like structures embedded in the body wall. They are found in the dorsal epidermis of female genital segments (e.g. in a spionid, Simon 1967 ; in an onuphid, Hsieh \& Simon 1990) or at the base of the branchial crown (e.g. in spirorbids; Daly \& Golding 1977). These structures usually are small in size, approximately $50 \mu \mathrm{m}$ in length. The wall of the sac is composed of a cellular layer. The lumen may be multiple branched (Hsieh \& Simon 1990).

Effects of hypoosmotic seawater on sperm. To elucidate the selective pressure of estuarine environments for self-fertilization, the effects of hyposaline seawater on sperm morphology were examined. Five salinity levels, $0,5,10,20$ (as the control) and 30\%, were prepared using filtered distilled water and seawater. Indi- viduals were collected from the field in October and November 1995 and kept in 20\% $S$ seawater for $1 \mathrm{~d}$ before use. Individuals were then blotted dry and male segments were cut into pieces of approximately equal length (about $2 \mathrm{~mm}$ long). Each piece was promptly moved to a small petri dish and covered with 100 to $150 \mu$ water drawn randomly from one of the 5 seawater treatments. The petri dishes were covered to minimize evaporation. The coeloms were opened and minced using cleaned forceps to release sperm. The petri dishes were gently but thoroughly agitated to mix the sperm in the water. After 10 min, drops of sperm were placed on circular cover glasses, fixed in $4 \%$ formaldehyde and glutaraldehyde vapors for $30 \mathrm{~min}$ and post-fixed in $1 \% \mathrm{OsO}_{4}$ vapors for another $30 \mathrm{~min}$. They were then dehydrated, critical point dried, sputtercoated with gold, and examined using a Hitachi S-2500 SEM (scanning electron microscope).

\section{RESULTS}

Isolation experiment. In the isolation experiments, 10 out of 29 control groups and 10 out of 62 isolated individuals produced viable larvae (Table 1), indicating that the isolated individuals either self-fertilized or stored sperm before isolation.

The number of eggs produced in each batch from isolated individuals ranged from approximately 30 to 2000 . The fertilization rates were similar among treatments and were often high, ranging from 80 to $100 \%$, except for several lower rates ( 30 to $65 \%$ ) in trial 3 (Table 1 ).

Coelomic ova experiment. Embryos and larvae were not produced ( $0 \%$ fertilization rate) when the coelomic ova received no sperm. The proportions of fertilized ova reaching the embryo stage in self-fertilization ranged from 16.6 to $91.7 \%$, whereas those of the outcross ranged from 25.0 to $94.7 \%$ (Table 2). The proportion of fertilized ova reaching the settlement stage was 5.4 to $46.9 \%$ in the self-fertilization treatment and 1.5 to $48.0 \%$ in the outcross treatment (Table 2). The differ-

Table 1. Laonome albicingillum. Comparisons of viable larval production between the control ( 3 individuals reared together) and isolation treatment (individuals reared alone). Numbers of larvae produced were the sum of larvae produced during the experiment period. n: total replicates used. Fertilization rate is expressed as percent of larvae produced relative to eggs spawned. Spawning occurred spontaneously in laboratory conditions

\begin{tabular}{|lcccc|}
\hline $\begin{array}{l}\text { Experimental trial and } \\
\text { treatment }\end{array}$ & $\begin{array}{c}\text { Number of replicates } \\
\text { producing offspring/n }\end{array}$ & $\begin{array}{c}\text { Number of batches } \\
\text { produced }\end{array}$ & $\begin{array}{c}\text { Number of larvae } \\
\text { produced }\end{array}$ & $\begin{array}{c}\text { Fertilization } \\
\text { rate }(\%)\end{array}$ \\
\hline 1 Control & $2 / 12$ & 2 & 186 & $80.4-95.3$ \\
Isolation & $1 / 28$ & 1 & 31 & 100.0 \\
2 Control & $2 / 8$ & 2 & 1394 & $91.1-99.6$ \\
Isolation & $1 / 16$ & 2 & 567 & $97.0-98.1$ \\
3 Control & $6 / 9$ & 8 & 1765 & $30.3-100.0$ \\
Isolation & $8 / 18$ & 14 & 4974 & $35.0-100.0$ \\
\hline
\end{tabular}


Table 2. Laonome albicingillum. Comparisons of offspring production between self-and outcross fertilization. Control: ova without sperm; selfing: ova with sperm from same individual; outcross: ova with sperm from another individual; ova used: total number of fertilized ova used. Embryo or larva production $(\%)$ is the percentage of fertilized ova that reach embryo or larval settlement stage. E: embryo stage; L: larval settlement stage. - not performed or recorded. ns: not significant; $\cdots p<0.01$

\begin{tabular}{|c|c|c|c|c|c|c|c|c|c|c|c|}
\hline \multirow{3}{*}{$\begin{array}{l}\text { Individual } \\
\text { number }\end{array}$} & \multicolumn{3}{|c|}{ Control } & \multicolumn{3}{|c|}{ Selfing } & \multicolumn{3}{|c|}{ Outcross } & \multicolumn{2}{|c|}{$G$-test } \\
\hline & \multirow{2}{*}{$\begin{array}{l}\text { Ova } \\
\text { used }\end{array}$} & \multicolumn{2}{|c|}{ Production $(\%)$} & \multirow{2}{*}{$\begin{array}{l}\text { Ova } \\
\text { used }\end{array}$} & \multicolumn{2}{|c|}{ Production (\%) } & \multirow{2}{*}{$\begin{array}{l}\text { Ova } \\
\text { used }\end{array}$} & \multicolumn{2}{|c|}{ Production (\%) } & \multirow[t]{2}{*}{$E$} & \multirow[t]{2}{*}{$\mathrm{L}$} \\
\hline & & $E$ & $\mathrm{~L}$ & & $E$ & $\mathrm{~L}$ & & E & $\mathrm{L}$ & & \\
\hline 1 & 11 & 0 & 0 & 10 & 90.0 & - & - & - & - & & \\
\hline 2 & 21 & 0 & 0 & 22 & 54.5 & - & - & - & - & & \\
\hline 3 & 16 & 0 & 0 & 49 & 59.2 & - & - & - & - & & \\
\hline 4 & 119 & 0 & 0 & 161 & 74.5 & 21.7 & 65 & 66.2 & 1.5 & ns & . \\
\hline 5 & 41 & 0 & 0 & 191 & 59.7 & 24.1 & 46 & 67.4 & 26.1 & ns & ns \\
\hline 6 & 45 & 0 & 0 & 60 & 80.0 & 26.7 & 37 & 75.7 & 24.3 & ns & ns \\
\hline 7 & 52 & 0 & 0 & 61 & 41.0 & 27.9 & 36 & 50.0 & 22.2 & ns & ns \\
\hline 8 & 71 & 0 & 0 & 56 & 80.4 & 5.4 & 77 & 27.3 & 3.9 & $\cdot \cdot$ & ns \\
\hline 9 & - & - & - & 12 & 16.6 & - & 15 & 33.3 & - & ns & \\
\hline 10 & - & - & - & 99 & 90.9 & - & 57 & 94.7 & - & ns & \\
\hline 11 & - & - & - & 12 & 33.3 & - & 12 & 25.0 & - & ns & \\
\hline 12 & - & - & - & 44 & 50.0 & 36.4 & 43 & 39.5 & 27.9 & ns & ns \\
\hline 13 & - & - & - & 98 & 28.6 & 17.3 & 271 & 49.4 & 10.7 & $\cdot \cdot$ & ns \\
\hline 14 & - & - & - & 145 & 91.7 & 46.9 & 102 & 93.1 & 48.0 & ns & ns \\
\hline 15 & - & - & - & 17 & 47.0 & 5.9 & 27 & 59.2 & 148 & ns & $\mathrm{ns}$ \\
\hline
\end{tabular}
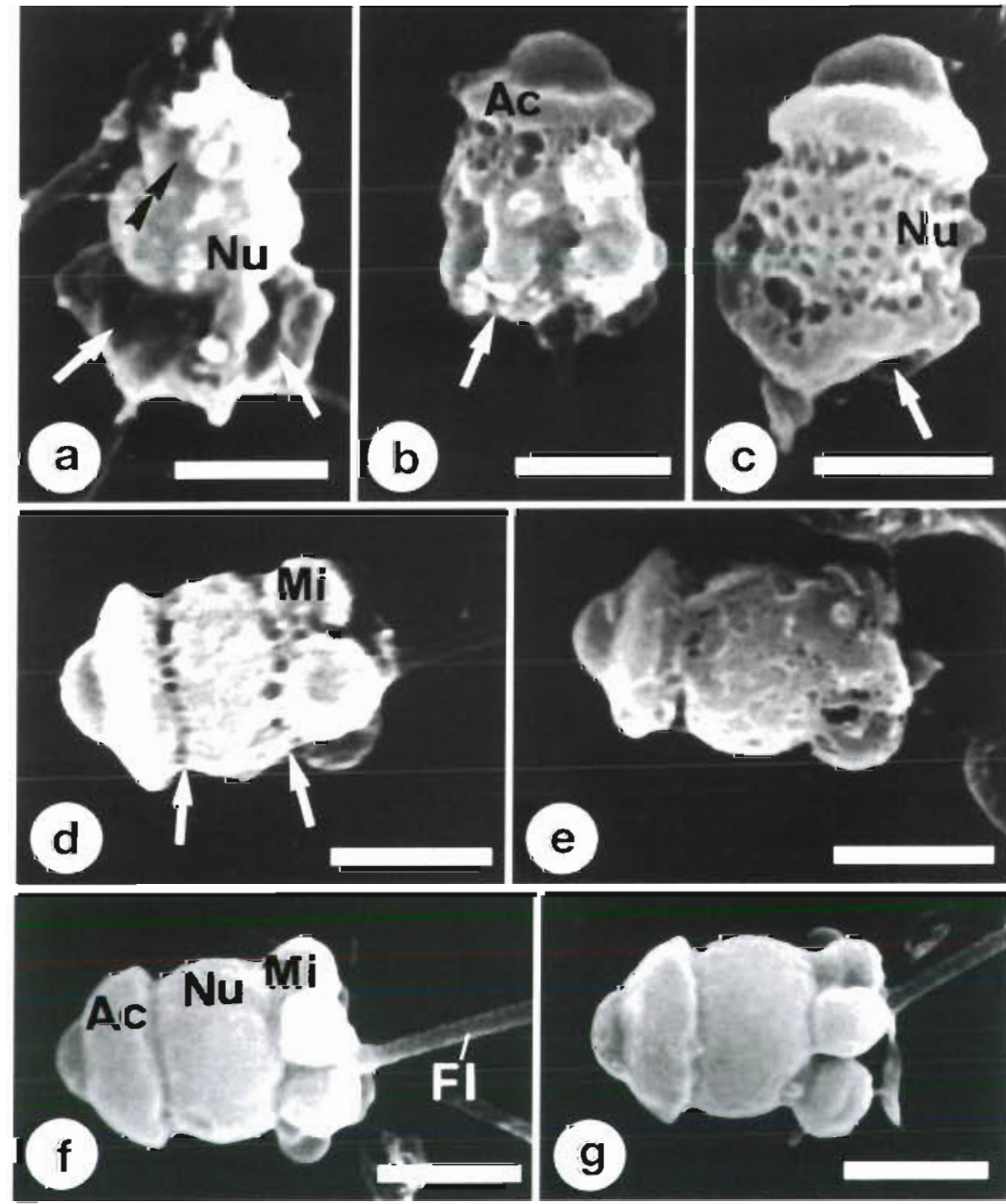

Fig. 1. Effects of salinity on sperm morphology in the sabellid Laonome albicingillum. (a) At $0 \%$ Salinity (S), acrosome (double arrow head) and mitochondria (arrows) are destroyed. $(b, c)$ At $5 \%, S$, numerous pores are in membranes, acrosome is retained but mitochondria disappear (arrow). $(d, e)$ At $10 \%$ S, membranes are stretched at the junctions between nucleus and acrosome and mitochondria (arrow). Also notice that membranes are worn out. (f, g) At 20 and $30 \%$, respectively, the membranes are intact and the sperm retain their integrity. Ac: acrosome; $\mathrm{Mi}$ : mitochondria; Nu: nucleus; Fl: flagellum. Scale bars $=1 \mu \mathrm{m}$ 
ences between paired treatments were not significant in 10 out of 12 comparisons at the embryo stage, and 8 out of 9 at the settlement stage (Table 2).

Tissue examination. The tissue sections examined did not reveal any structures which could serve as seminal receptacles, indicating that sperm storage is unlikely.

Effects of hypoosmotic seawater on sperm morphology. At 20 and $30 \%$ S, the sperm was elliptical in shape with a conical acrosome and 4 or 5 spherical mitochondria (Fig 1f, g). The membranes binding the whole sperm were intact and smooth, the acrosome was located on the top of the nucleus, the mitochondria were arranged in a circle at the base of the nucleus, and a long flagellum extended out axially from the posterior of the nucleus (Fig. 1f, g). In contrast, salinity below $10 \%$ had adverse effects on sperm structures. At 5 and $10 \% \mathrm{~S}$, the sperm were less identifiable or lost their organelles, and the mitochondria disappeared (Fig. 1b-e). The membranes were stretched at the junctions between the nucleus and the acrosome and between the mitochondria (Fig. 1d). Moreover, the membranes were torn or contained numerous pores (Fig. 1b-e). At $0 \%$ S, most of the sperm disintegrated, but some sperm still retained their shape and possessed pores in their membranes. In addition, the integrity of the sperm had been greatly destroyed, and the acrosome and mitochondria had fallen apart (Fig 1a).

\section{DISCUSSION}

The present study provides 4 relevant forms of evidence favoring the likelihood of self-fertilization in Laonome albicingillum. The evidence includes: (1) sperm morphology is destroyed by hypoosmotic seawater (see Fig. 1), suggesting selective pressure from an estuarine environment; (2) the species lacks sperm storage capacity, suggesting there is less of a chance of transferring sperm to other individuals; (3) isolated individuals produce viable offspring (see Table 1); (4) mature ova fertilized by the same individual's sperm develop normally and larvae settle successfully (see Table 2), suggesting no immediate inbreeding depression.

Does outcross occur in the natural population of Laonome albicingillum? In general, an outcross system involving free sperm transfer and sperm storage is recorded mainly in brooding species (e.g. in spionids: Simon 1967, Rice 1978; spirorbids: Daly \& Golding 1977; an onuphid: Hsieh \& Simon 1990), disagreeing with the broadcast spawning of $L$. albicingillum. However, it needs to be stressed that although in $L$. albicingillum a free sperm transfer system involving sperm storage is not expected, in the bryozoan Membranipora membranacea, temporary concentration of sperm in lophophores during spawning was recorded (Temkin 1994). Moreover, L. albicingillum has high population density in the natural environment, outcross fertilization may be ensured by spawning at flood time when water salinity is elevated, regardless of its very asynchronous spawning (less than $15 \%$ of individuals spawn at the same time, see 'Introduction' and 'Materials and methods'). As a result, the above arguments cannot fully support the prevalence of selfing in natural populations, and the possibility of outcross fertilization cannot be dismissed.

There are, however, some disadvantages in outbreeding, such as the loss of gametes due to dispersal (Shields 1993, Waser 1993, Levitan \& Petersen 1995). The ecological conditions imposed on the breeding of the sabellid Laonome albicingillum are even more crucial. Given the unfavorable, hypoosmotic environment and the dilution problem of gametes upon release into ambient water, the most favorable situation is that eggs and sperm can encounter each other within a space as confined and proximate as possible, as in selfing in a hermaphrodite.

Unfavorable conditions for pollination or competition for pollinators in plant species have been considered to be driving forces in the evolution toward inbreeding (Jain 1976). Inbreeding of marine invertebrate species has been proposed to be associated with unstable habitats, such as tidal pools and estuaries (Knowlton \& Jackson 1993). In an estuary, selfing could be favored in order to avoid hypoosmotic stress, since invertebrate sperm are known to be incapable of osmoregulation upon release and rapidly lose their motility in low salinity (Clark 1981). In the present study, sperm morphology in Laonome albicingillum was maintained

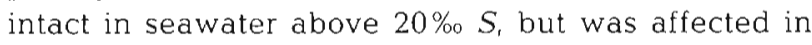
seawater with lower than $10 \% \mathrm{~S}$. In the latter, the fine structures of the sperm were damaged (see Fig. 1). Thus, in the natural habitat of the Tan-Shui estuary, where water salinity peaks around 10 to $33 \%$ in the lower estuary and 0 to $15 \%$ in the upper estuary at floods and drops to as low as $0 \%$ at ebbs (Hsieh 1995b. see 'Introduction'), hypoosmotic pressure is a selection force in the favoring of selfing in L. albicingillum.

Increasing evidence from various organisms, particularly plants and insects, shows that costs of inbreeding are not always found (Jain 1976, Shields 1993, Waser 1993). Inbreeding can result in the building up of coordinated gene complexes and permit local adaptation (Knowlton \& Jackson 1993, Pusey \& Wolf 1996). In the routine inbreeding of the colonial ascidian Botryllus schlosseri, the success of fertilization, embryogenesis and larval metamorphosis increased significantly in crosses with closely related neighbors (Grosberg 1987), and in a harpacticoid copepod Tigriopus californicus, offspring from crosses within a single population in high 
intertidal and supratidal rock pools showed improved tolerance to extreme salinities (Burton 1986). The present study on Laonome albicingillum provides convincing evidence that self-fertilized (extreme inbreeding) progeny do not differ in survivorship, development, and settlement from outbred ones, suggesting a lack of inbreeding depression in the early stages of life.

Deleterious effects of inbreeding occur in many organisms, including the spirorbid polychaete Pileolaria pseudomilitaris (Beckwitt 1982). Such effects may be delayed a generation or more, as recorded in the freshwater snail and in a bryozoan (Jarne et al. 1991, Hunter \& Hughes 1993). Although there seems to be no immediate inbreeding depression during the early life stages in Laonome albicingillum, whether longterm effects exist deserves further study.

Acknowledgements. The author thanks C. P. Chen, F. S. Chia and J. L. Simon for their constructive comments and continuous encouragement. The author is gratefuil to 3 anonymous reviewers for their valuable comments and suggestions. This study was supported by NSC Grants NSC820211B001020 and NSC830211B001012.

\section{LITERATURE CITED}

Beaumont AR, Budd MD (1983) Effects of self-fertilization and other factors on the early development of the scallop Pecten maximus. Mar Biol 76:285-289

Beckwitt R (1982) Electrophoretic evidence for self fertilization in 2 species of spirorbid polychaetes. Bull South Calif Acad Sci 81(2):61-68

Brazeau DA, Lasker HR (1992) Reproductive success in the Caribbean octocoral Briareum asbestinum. Mar Biol 114: $157-163$

Burton RS (1986) Evolutionary consequences of restricted gene flow among natural populations of the copepod, Tigriopus californicus. Bull Mar Sci 39(2):526-535

Charlesworth D, Charlesworth B (1987) Inbreeding depression and its evolutionary consequences. Ann Rev Ecol Syst 18:237-268

Clark WC (1981) Sperm transfer mechanisms: some correlates and consequences. NZ J Zool 8:49-65

Daly JM, Golding DW (1977) A description of the spermatheca of Spirorbis spirorbis (L.) (Polychaeta: Serpulidae) and evidence for a novel mode of sperm transmission. J Mar Biol Ass UK 57:219-227

Ghuselin MT (1969) The evolution of hermaphroditism among animals. Q Rev Biol 44:189-208

Ghiselin MT (1987) Evolutionary aspects of marine invertebrate reproduction. In: Giese AC, Pearse JS, Pearse VB (eds) Reproduction of marine invertebrates, Vol 9 , General aspects: seeking unity in diversity. Blackwell Scientific Publications and The Boxwood Press, California, p 609-665

Grosberg RK (1987) Limited dispersal and proximity-dependent mating success in the colonial ascidian Botryllus schlosseri. Evolution 41(2):372-384

Heath DJ (1977) Simultaneous hermaphroditism: cost and benefit. J Theor Biol 64:363-373

Hintz JL, Lawrence JM (1994) Acclimation of gametes to reduced salinity prior to spawning in Luidia clathrata (Echinodermata: Asteroidea). Mar Biol 120:443-446
Hsieh HL (1995a) Laonome albicingillum, a new fan worm species (Polychaeta: Sabellidae: Sabellinae) from Taiwan. Proc Biol Soc Wash 108(1):130-135

Hsieh HL (1995b) Spatial and temporal patterns of polychaete communities in a subtropical mangrove swamp: influences of sediment and microhabitat. Mar Ecol Prog Ser $127: 157-167$

Hsieh HL, Simon JL (1990) The sperm transfer system in Kinbergonuphis simoni (Polychaeta: Onuphidae). Biol Bull 178:85-93

Hunter E, Hughes RN (1993) Self-fertilization in Celleporella hyalina. Mar Biol 115:495-500

Jain SK (1976) The evolution of inbreeding in plants. Ann Rev Ecol Syst 7:469-495

Jarne P, Finot L, Delay B, Thaler L (1991) Self-fertilization versus cross-fertiluzation in the hermaphroditic freshwater snail Bulinus globosus. Evolution 45(5):1136-1146

Kawamura K, Fujita H, Nakauchi M (1987) Cytological characterization of self incompatibility in gametes of the ascidian Ciona intestinalis. Dev Growth Differ 29(6):627-642

Knowlton N, Jackson JBC (1993) Inbreeding and outbreeding in marine invertebrates. In: Thornhill NW (ed) The natural history of inbreeding and outbreeding: theoretical and empirical perspectives. The University of Chicago Press, Chicago, p 200-249

Levitan DR, Petersen C (1995) Sperm limitation in the sea. Trends Ecol Evol 10(6):228-231

Maynard Smith J (1973) The evolution of sex. Cambridge University Press, Cambridge

Pennington JT (1985) The ecology of fertilization of echinoid eggs: the consequences of sperm dilution, adult aggregation, and synchronous spawning. Biol Bull 169:417-430

Pusey A. Wolf $M$ (1996) Inbreeding avoidance in animals. Trends Ecol Evol 11(5):201-206

Rice SA (1978) Spermatophores and sperm transfer in spionid polychaetes. Trans Am Microsc Soc 97(2): 160-170

SAS Institute (1985) SAS user's guide: statistics, 5th edn. SAS Institute, Cary, NC

Shields WM (1993) The natural and unnatural history of inbreeding and outbreeding. In: Thornhill NW (ed) The natural history of inbreeding and outbreeding: theoretical and empirical perspectives. The University of Chicago Press, Chicago, p 143-169

Shih JT, Lue KY, Wang CH (1991) Crab fauna and the activities of ten crab species in Tanshui mangrove swamp of Taiwan. Ann Taiwan Mus 34:121-140 (in Chinese with English abstract)

Simon JL (1967) Reproduction and larval development of Spio setosa. Bull Mar Sci 17:398-431

Sokal RR, Rohlf FJ (1981) Biometry. WH Freeman and Co, San Francisco

Temkin MH (1994) Gamete spawning and fertilization in the gymnolaemate bryozoan Membranipora membranacea Biol Bull 187:143-155

Waser NM (1993) Population structure, optimal outbreeding, and assortative mating in angiosperms. In: Thornhill NW (ed) The natural history of inbreeding and outbreeding: theoretical and empirical perspectives. The University of Chicago Press, Chicago, p 173-199

Wu JT, Sheu MK, O-Yang T (1993) Periodic changes of the phytoplankton assemblages in estuary of Tansui River, Taiwan. Bot Bull Acad Sin 34:235-242

Yund PO (1990) An in situ measurement of sperm dispersal in a colonial marine hydroid. J Exp Zool 253:102-106

Yund PO, McCartney MA (1994) Male reproductive success in sessile invertebrates: competition for fertilization. Ecology 75(8):2151-2167

Manuscnpt first received: October 4, 1996

Revised version accepted: January 7, 1997 